\title{
Management of Laryngopharyngeal Reflux in Asia
}

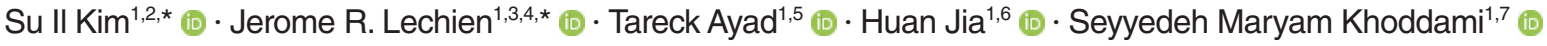

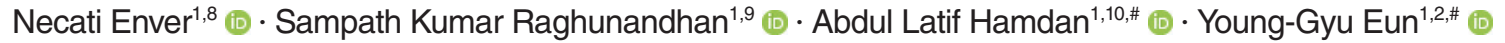 \\ ${ }^{1}$ Laryngopharyngeal Reflux Study Group of Young Otolaryngologists of the International Federation of Oto-rhino-laryngological Societies, Paris, \\ France; ${ }^{2}$ Department of Otolaryngology-Head and Neck Surgery, Kyung Hee University School of Medicine, Seoul, Korea, ${ }^{3}$ Department of \\ Anatomy and Experimental Oncology, Mons School of Medicine, UMONS Research Institute for Health Sciences and Technology, University of \\ Mons, Mons; ${ }^{4}$ Department of Otorhinolaryngology and Head and Neck Surgery, CHU Saint-Pierre, Faculty of Medicine, Université Libre de \\ Bruxelles, Brussels, Belgium; ' Division of Otolaryngology-Head and Neck Surgery, Centre Hospitalier de l'Université de Montréal, Montreal, \\ Québec, Canada; ${ }^{6}$ Department of Otorhinolaryngology and Head and Neck Surgery, Shanghai Ninth People s Hospital, Shanghai Jiaotong \\ University School of Medicine, Shanghai, China; ${ }^{7}$ Larynx Function Laboratory, Department of Speech Therapy, School of Rehabilitation, Tehran \\ University of Medical Sciences, Tehran, Iran; ${ }^{8}$ Department of Otolaryngology, Marmara University Pendik Training and Research Hospital, \\ Istanbul, Turkey; ${ }^{9}$ Department of Otology, Neurotology and Skullbase Surgery, Madras ENT Research Foundation, Chennai, India; ${ }^{10}$ Department \\ of Otorhinolaryngology-Head and Neck Surgery, American University of Beirut Medical Center, Beirut, Lebanon
}

Objectives. This study was conducted to investigate the current practices of Asian otolaryngologists for laryngopharyngeal reflux (LPR).

Methods. An online survey about LPR was sent to 2,000 members of Asian otolaryngological societies, and a subgroup analysis was performed between Western and Eastern Asian otolaryngologists. The survey was conducted by the Laryngopharyngeal Reflux Study Group of Young Otolaryngologists of the International Federation of Oto-rhino-laryngological Societies.

Results. Among approximately 1,600 Asian otolaryngologists, 146 completed the survey (62 from Western Asian countries, 84 from Eastern Asian countries). A substantial majority (73.3\%) of the otolaryngologists considered LPR and gastroesophageal reflux disease to be different diseases. The symptoms thought to be closely related to LPR were coughing after lying down, throat clearing, and globus sensation. The findings thought to be closely related to LPR were posterior commissure granulations and hypertrophy, arytenoids, and laryngeal erythema. The respondents indicated that they mostly diagnosed LPR $(70 \%)$ after an empirical therapeutic trial of proton pump inhibitors (PPIs). Although multichannel intraluminal impedance-pH (MII-pH) monitoring is a useful tool for diagnosing nonacid or mixed LPR, 78\% of Asian otolaryngologists never or very rarely used MII-pH. Eastern Asian otolaryngologists more frequently used once-daily PPIs ( $64.3 \%$ vs. $45.2 \%, P=0.021)$, whereas Western Asian otolaryngologists preferred to use twice-daily PPIs $(58.1 \%$ vs. $39.3 \%, P=0.025)$. The poor dietary habits of patients were considered to be the main reason for therapeutic failure by Asian otolaryngologists (53.8\%). Only $48.6 \%$ of Asian otolaryngologists considered themselves to be adequately knowledgeable and skilled regarding LPR.

Conclusion. Significant differences exist between Western and Eastern Asian otolaryngologists in the diagnosis and treatment of LPR. Future consensus statements are needed to establish diagnostic criteria and therapeutic regimens.

Keywords. Laryngopharyngeal Reflux; Otolaryngologist; Disease Management; Therapeutics; Surveys and Questionnaires

\footnotetext{
- Received October 8, 2019

Revised November 14, 2019

Accepted December 14, 2019

- Corresponding author: Young-Gyu Eun

Department of Otolaryngology-Head and Neck Surgery, Kyung Hee

University Medical Center, 23 Kyungheedae-ro, Dongdaemun-gu,

Seoul 02447, Korea

Tel: +82-2-958-8474, Fax: +82-2-958-8470

E-mail: ygeun@hanmail.net
}

\footnotetext{
- Co-Corresponding author: Abdul Latif Hamdan

Department of Otolaryngology, American University of Beirut,

Beirut 11-0236, Lebanon

Tel: +961-1-350000

E-mail: ah77@aub.edu.lb

*These authors contributed equally to this article's supervision and should be considered as co-first* and co-last* senior authors.
}

Copyright $\odot 2020$ by Korean Society of Otorhinolaryngology-Head and Neck Surgery.

This is an open-access article distributed under the terms of the Creative Commons Attribution Non-Commercial License (https://creativecommons.org/licenses/by-nc/4.0) which permits unrestricted non-commercial use, distribution, and reproduction in any medium, provided the original work is properly cited. 


\section{INTRODUCTION}

Laryngopharyngeal reflux (LPR)—also known as extraesophageal reflux - is an inflammatory condition of the upper aerodigestive tract related to the direct and indirect effects of gastric or duodenal content reflux, which induces morphological changes in the upper aerodigestive tract [1]. Gastroesophageal reflux disease (GERD) is also caused by the reflux of gastric content, but the two conditions show many differences in symptoms, manifestations, and response to treatment [2]. The most important difference between LPR and GERD is that the majority of patients with LPR do not have esophagitis; furthermore, fewer digestive-related symptoms are generally reported in patients with GERD [3].

According to a meta-analysis, the prevalence of GERD-associated symptoms varies among countries [4]. The highest prevalence of GERD-associated symptoms was reported in a Central American study (19.6\%) and the lowest in Asia (10.0\%), particularly in Southeast Asian countries (7.4\%) [4]. However, the prevalence of LPR throughout the world has not been a major focus of research. Some previous studies reported that the prevalence of LPR was $34.4 \%, 18.8 \%$, and $5.0 \%$ in the United Kingdom, Greece, and the Fuzhou region in China, respectively, according to the reflux symptom index (RSI), but the authors did not confirm the LPR diagnoses through objective testing [5-7].

The ambulatory 24-hour double-probe $\mathrm{pH}$ monitoring test, which was developed and used for diagnosing GERD, has been regarded as the gold standard for diagnosing LPR [8]. However, this approach does not detect nonacid reflux episodes in either the esophagus or the hypopharyngeal cavity. A more recently developed technique, multichannel intraluminal impedance-pH (MII-pH) monitoring, is the most reliable method to precisely diagnose acid, nonacid, and mixed reflux [9]. Another way to diagnose LPR is to conduct an empirical proton pump inhibitor (PPI) trial for 3 months in patients with LPR-associated symptoms and findings [10]. Although PPIs are the most commonly prescribed class of medications for reflux symptoms [11], place-

\section{H I G H L I G H T S}

- This study was conducted to investigate the current practices of Asian otolaryngologists for laryngopharyngeal reflux (LPR).

- Approximately $75 \%$ of otolaryngologists considered LPR and gastroesophageal reflux disease to be different diseases.

- Most Asian otolaryngologists never or very rarely used multichannel intraluminal impedance-pH monitoring to diagnose LPR.

- Only about half of Asian otolaryngologists considered themselves to be skilled regarding LPR.

- Significant differences exist among Asian otolaryngologists in the management of LPR. bo-controlled randomized trials have failed to demonstrate any therapeutic benefit of PPIs, which are less effective in patients with nonacid or mixed reflux [12]. Magaldrate may be useful for many patients with nonacid or mixed reflux $[9,13]$. It is also important for physicians to provide counseling to patients on lifestyle factors as a way to treat reflux symptoms, but such counseling is often overlooked [11]. To summarize, as a result of various limitations in this field, a unified set of methods is still not used to diagnose and treat LPR. The aim of this study was to investigate and compare the current practices and opinions of Western and Eastern Asian otolaryngologists for LPR.

\section{MATERIALS AND METHODS}

\section{Study design}

An international survey was created by the Laryngopharyngeal Reflux Study Group of Young Otolaryngologists of the International Federation of Oto-rhino-laryngological Societies for assessing the current knowledge and practice of otolaryngologists in the management of LPR around the world. The survey was developed with SurveyMonkey (San Mateo, CA, USA), so that each participant could complete the survey only once. The survey was developed in iterative fashion, with drafts revised by both three certified otolaryngologists. The survey included 21 questions divided into five sections: definition and epidemiology (3); clinical presentation (4); diagnostic approach (3); treatment (10) and skills (1) (Supplementary Fig. 1).

The survey was emailed on two occasions to 1,600 Asian otolaryngologists through various networks. First, the survey was sent to Asian otolaryngologists who had attended the 2017 International Federation of Oto-rhino-laryngological Societies meeting (Paris, France). Second, the otolaryngologists of the LPR Study Group also emailed the members of several scientific societies e.g. Indian, Chinese, Lebanese, Turkish, and Korean ENT societies. Otolaryngologists were also invited to share the survey with their colleagues. Responses were collated anonymously. Only complete responses were considered for the analysis. An additional analysis was made to compare the practice of Western and Eastern Asian otolaryngologists. Western countries consisted of the countries on the western side of India. Eastern countries consisted of the countries on the eastern side of India. India and Russia were included in the Eastern countries.

\section{Statistical analysis}

IBM SPSS ver. 22.0 (IBM Corp., Armonk, NY, USA) was used to perform the statistical analyses. A level of $P<0.05$ was used to determine statistical significance. The differences in responses between Western and Eastern Asian otolaryngologists were evaluated using the chi-square test. 


\section{RESULTS}

Approximately 1,600 Asian otolaryngologists received the survey, of whom 146 completed it. Of the respondents, 62 and 84 were from Western and Eastern Asian countries, respectively. The characteristics of the groups are presented in Table 1.

\section{LPR definition, prevalence, and incidence in upper aerodigestive tract diseases}

The majority of otolaryngologists $(73.3 \%)$ considered LPR and GERD to be different diseases sharing some common patho-

Table 1. Characteristics of Asian otolaryngologists

\begin{tabular}{lccc}
\hline Practice characteristics & Western Asian & Eastern Asian & Total \\
\hline Years of practice & $12.47 \pm 7.6$ & $11.66 \pm 7.9$ & $12.0 \pm 7.7$ \\
Academic practice & 35 & 46 & 81 \\
Private practice & 8 & 17 & 25 \\
Academic and private & 18 & 20 & 38 \\
$\quad$ practice & 1 & 1 & 2 \\
Lacking information & & & \\
\hline
\end{tabular}

Values are presented as mean \pm standard deviation. The groups were comparable regarding the types of practice (academic vs. private vs. academic and private). physiological mechanisms, while $14.4 \%$ of otolaryngologists considered GERD and LPR to be the same disease. The prevalence of LPR was evaluated as $25.5 \%$, without a significant difference between the two groups.

The Western and Eastern Asian otolaryngologists indicated that LPR may be associated with the development of Reinke's edema, recurrent sore throat, chronic cough, and chronic voice disorders. Eastern Asian otolaryngologists reported a stronger association between LPR and recurrent sore throat than Western Asian otolaryngologists $(P=0.018)$. However, they did not believe that LPR is associated with the development of chronic rhinosinusitis, chronic and acute media otitis, Eustachian tube dysfunction, laryngotracheal stenosis, nodules, vocal fold hemorrhage and polyps, or nasal obstruction. The respondents did not acknowledge the involvement of LPR in bronchial hypersensitivity (Fig. 1).

\section{LPR symptoms and findings}

The symptoms associated with LPR were identified and listed based on the reflux symptom score [13]. The symptoms thought to be closely related to LPR were coughing after lying down or after eating $(80.5 \%)$, throat clearing $(79.0 \%)$, globus sensation (73.0\%), chronic cough (72.3\%), stomach acid coming up $(66.7 \%)$,
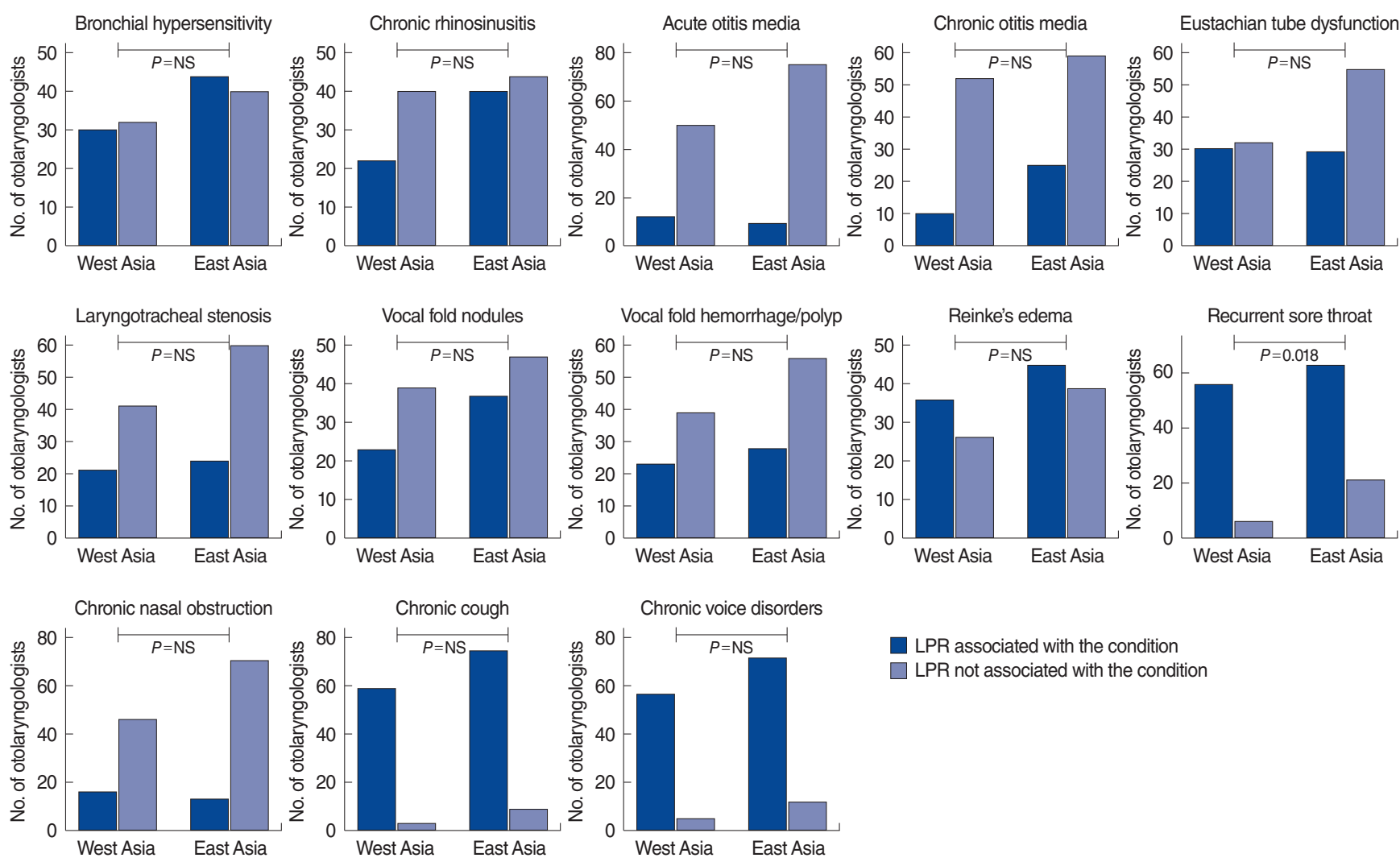

LPR associated with the condition

$\square$ LPR not associated with the condition

Fig. 1. Clinical findings associated with reflux in the development of upper aerodigestive tract diseases (Western vs. Eastern Asian otolaryngologists). The Y-axis corresponds to the number of otolaryngologists who agreed or not with a certain association. NS, not significant; LPR, laryngopharyngeal reflux. 
sensation of sticky mucus in the throat $(61.8 \%)$, hoarseness $(61.8 \%)$, heartburn (54.0\%), throat pain (41.7\%), halitosis (31.2\%), odynophagia $(30.8 \%)$, dysphagia $(29.1 \%)$, tongue burning $(22.3 \%)$, chest pain (12.0\%), and breathing difficulties (11.1\%). Western Asian otolaryngologists were more aware of throat pain as a symptom (50.0\%) than Eastern Asian otolaryngologists $(35.7 \%$, $P=0.011)$.

The findings associated with LPR were identified and listed through the reflux sign assessment (RSA). The otolaryngologists considered the following findings to be closely associated with LPR: posterior commissure granulations $(83.1 \%)$, arytenoid or laryngeal erythema (78.1\%), posterior commissure hypertrophy $(73.7 \%)$, retrocricoid edema $(63.1 \%)$, pharyngeal erythema $(59.8 \%)$, endolaryngeal sticky mucus $(54.6 \%)$, vocal fold erythema $(50.7 \%)$, vocal fold edema $(44.0 \%)$, subglottic edema (43.0\%), vocal fold lesions (e.g., nodules, polyps, leukoplakia, ulceration, or granuloma; $41.6 \%)$, laryngeal ventricular edema $(34.5 \%)$, pharyngeal wall edema $(34.5 \%)$, subglottic erythema $(34.0 \%)$, coated tongue $(24.6 \%)$, tongue tonsil hypertrophy $(23.3 \%)$, uvula edema or erythema $(17.0 \%)$, anterior tonsillar pillar erythema (16.9\%), and anterior tonsillar pillar edema (12.1\%).

Compared with Western Asian otolaryngologists, Eastern Asian otolaryngologists were more likely to consider that arytenoid/ laryngeal erythema (70.0\% vs. $38.8 \%, P=0.038)$, coated tongue (30.1\% vs. $17.7 \%, P=0.003)$, and tongue tonsil hypertrophy (23.3\% vs. $8.4 \%, P=0.036)$ were closely associated with LPR. Western Asian otolaryngologists were more aware than Eastern Asian otolaryngologists of the associations between LPR and posterior commissure hypertrophy $(93.6 \%$ vs. $83.7 \%, P=0.017)$ and pharyngeal wall edema ( $40.4 \%$ vs. $30.0 \%, P=0.028)$.

\section{Diagnostic approaches}

Seventy percent of Asian otolaryngologists diagnosed LPR based on an improvement in both symptoms and signs following an empirical therapeutic trial. Both gastrointestinal (GI) endoscopy and transnasal esophagoscopy were infrequently used in the initial assessment of LPR (by $13.7 \%$ and $18.2 \%$ of otolaryngologists, respectively). The main reasons for prescribing GI endoscopy were reflux disease refractory to medical management $(48.6 \%)$, symptoms requiring long-term PPI therapy (Western Asian, 41.9\%; Eastern Asian, 26.2\%; $P=0.045)$, the presence of heartburn or stomach acid coming up (Western Asian, 12.9\%; Eastern Asian, $32.1 \% ; P=0.007)$, and elderly patients $(12.3 \%)$. In total, $11.0 \%$ of otolaryngologists recommended GI endoscopy or transnasal esophagoscopy to all LPR patients, while $14.4 \%$ thought that GI endoscopy is not important for LPR (Fig. 2). Regarding additional examinations, $83.2 \%$ and $72.7 \%$ of Asian otolaryngologists never or very rarely used single- and dual-probe $\mathrm{pH}$ monitoring, respectively; however, Western Asian otolaryngologists more frequently used dual-probe $\mathrm{pH}$ monitoring than Eastern Asian otolaryngologists $(P=0.032)$. Similarly, $78 \%$ of the otolaryngologists never or very rarely used MII-pH. The most important barriers to using $\mathrm{MII}-\mathrm{pH}$ or $\mathrm{pH}$ monitoring were inconvenience (56.4\%), cost (56.0\%), lack of time to perform the examination $(38.6 \%)$; lack of meaningfulness $(35.3 \%)$, and lack of time for training in interpretation (34.0\%). The inconvenience of the approach was the most important barrier for Eastern Asian otolaryngologists, in contrast to Western Asian otolaryngologists $(63.7 \%$ vs. $45.6 \%, P=0.003)$. Western Asian otolaryngologists more frequently considered a lack of time to perform the examination to be an important barrier than Eastern Asian otolaryngologists $(P=0.021)$.

Eastern Asian otolaryngologists were more aware of the use of oropharyngeal $\mathrm{pH}$ monitoring, as $3.7 \%$ used it, compared to $0 \%$ of Western Asian otolaryngologists $(P=0.048)$. The most important difference between the Western and Eastern Asian otolaryngologists concerned referrals of patients to a gastroenterologist, as $13.6 \%$ of Western Asian otolaryngologists never or rarely referred LPR patients to a gastroenterologist, in contrast to

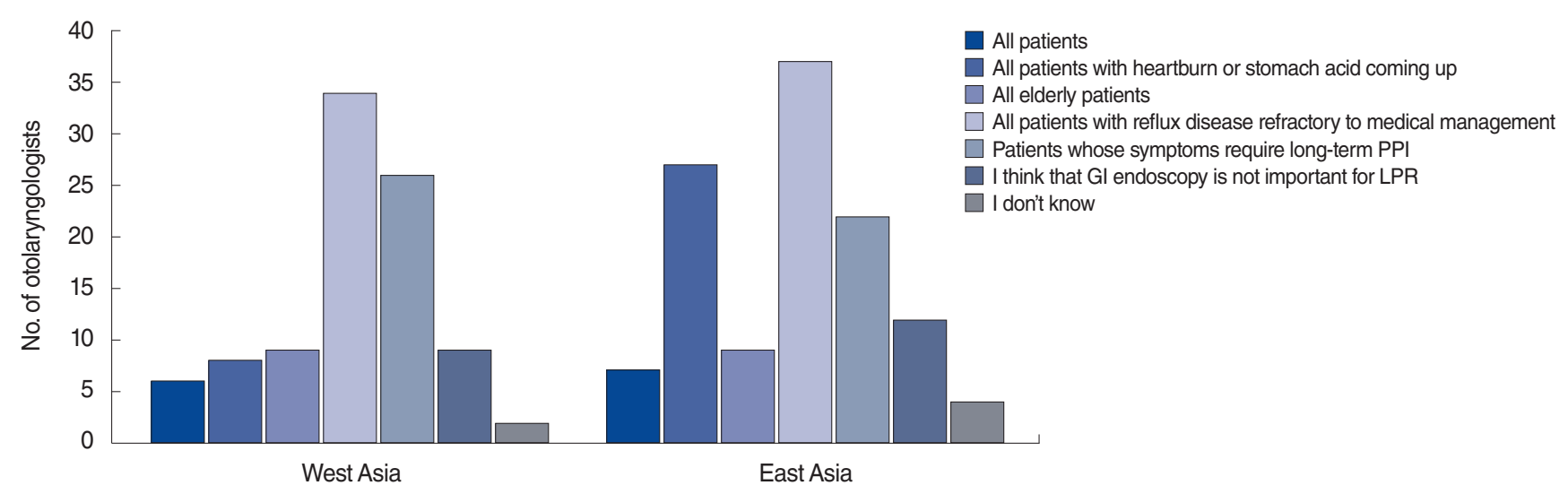

Fig. 2. The main reasons why Western and Eastern Asian otolaryngologists prescribed gastrointestinal (GI) endoscopy. The Y-axis corresponds to the number of otolaryngologists who endorsed a certain reason for prescribing Gl endoscopy (each otolaryngologist could select multiple reasons). PPI, proton pump inhibitor; LPR, laryngopharyngeal reflux. 


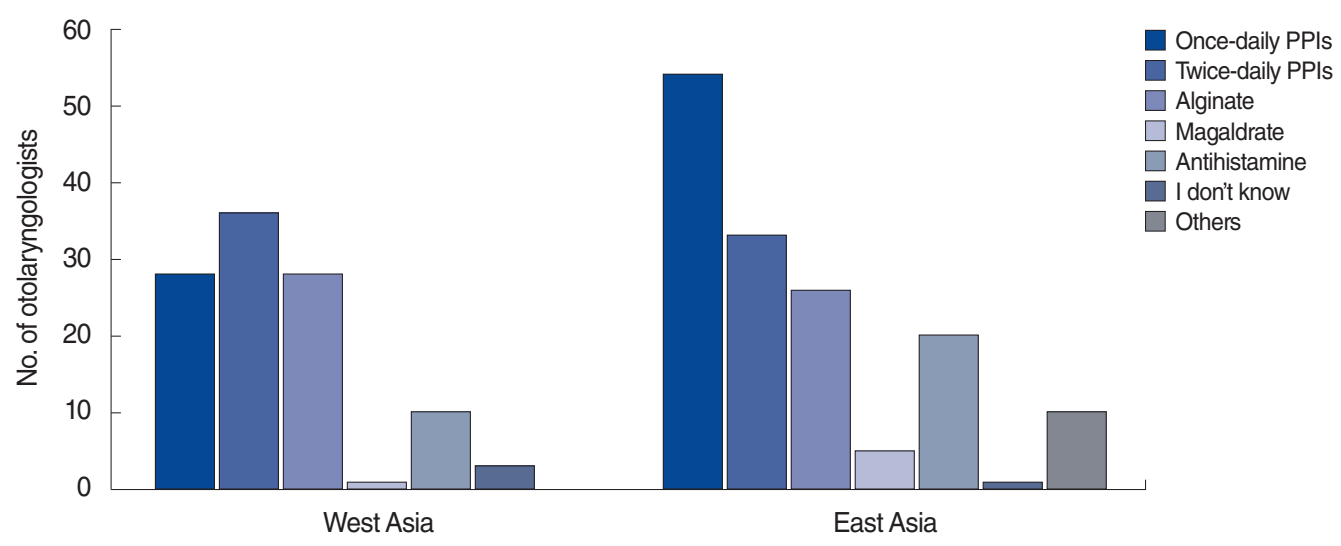

Fig. 3. Anti-reflux treatment options used by Western and Eastern Asian otolaryngologists. The Y-axis corresponds to the number of otolaryngologists who prescribed each drug (each otolaryngologist could select multiple options). Eastern Asian otolaryngologists more frequently used once-daily proton pump inhibitors (PPIs; $64.3 \%$ vs. $45.2 \%, P=0.021$ ), whereas Western Asian otolaryngologists preferred to use twicedaily PPIs (58.1\% vs. 39.3\%, $P=0.025)$.
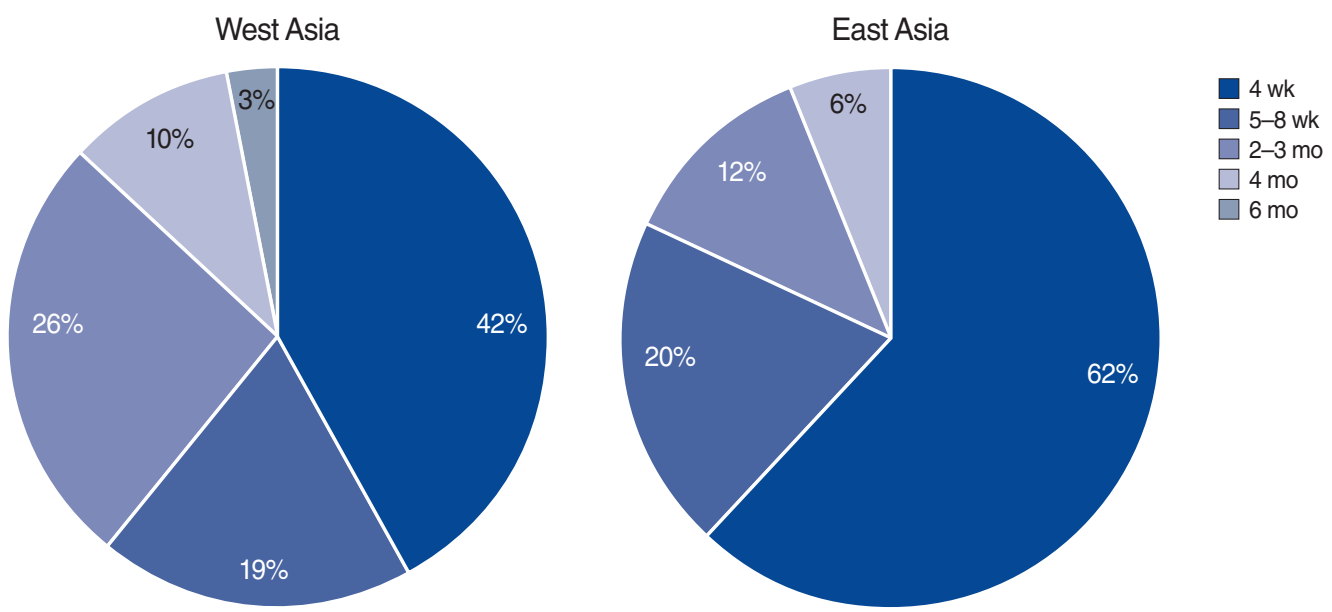

Fig. 4. Treatment duration differences between Western and Eastern Asian otolaryngologists. Western Asian otolaryngologists prescribed treatments with a longer duration than did Eastern Asian otolaryngologists $(P=0.048)$.

$50.6 \%$ of Eastern Asian otolaryngologists $(P=0.001)$.

\section{Treatment of LPR patients}

The different treatment options used by the otolaryngologists are presented in Fig. 3. Eastern Asian otolaryngologists more frequently used once-daily PPIs than Western Asian otolaryngologists (64.3\% vs. $45.2 \%, P=0.021)$, whereas Western Asian otolaryngologists preferred to use twice-daily PPIs (58.1\% vs. $39.3 \%, P=0.025)$. Additionally, $37 \%$ and $4.1 \%$ of Asian otolaryngologists used alginate and magaldrate for LPR treatment, respectively. H2-blockers were used by $20.5 \%$ of Asian otolaryngologists. Diet was considered to be an important factor in LPR treatment by $94.4 \%$ of Asian otolaryngologists. The treatment duration significantly varied between Western and Eastern Asia (Fig. 4), as Western Asian otolaryngologists prescribed treatments with a longer duration than did Eastern Asian otolaryngologists $(P=0.048)$.
Furthermore, $47.2 \%$ and $51.4 \%$ of Asian otolaryngologists, respectively, considered improvements in symptoms or in symptoms and findings as the therapeutic outcome. Thus, $41.0 \%$ and $14.6 \%$ of otolaryngologists, respectively, often or sometimes used patient-reported outcome questionnaires for diagnosis or treatment evaluation. Irrespective of the region, $73.6 \%$ of Asian otolaryngologists considered that $10 \%$ to $40 \%$ of patients showed a therapeutic response.

Furthermore, $24.2 \%$ and $15.5 \%$ of Western and Eastern Asian otolaryngologists, respectively, were aware of the existence of nonacid and mixed LPR $(P=0.024)$. The therapeutic regimens for nonacid LPR included a combination of PPIs with alginate or magaldrate $(25.6 \%)$, PPIs $(20.2 \%)$, alginate $(16.3 \%)$, a strict diet $(14.0 \%)$, surgery $(10.9 \%)$, and magaldrate $(5.4 \%)$. However, $7.8 \%$ of respondents indicated that they did not know what treatment is suitable for nonacid LPR.

Asian otolaryngologists believed that the main reasons for 

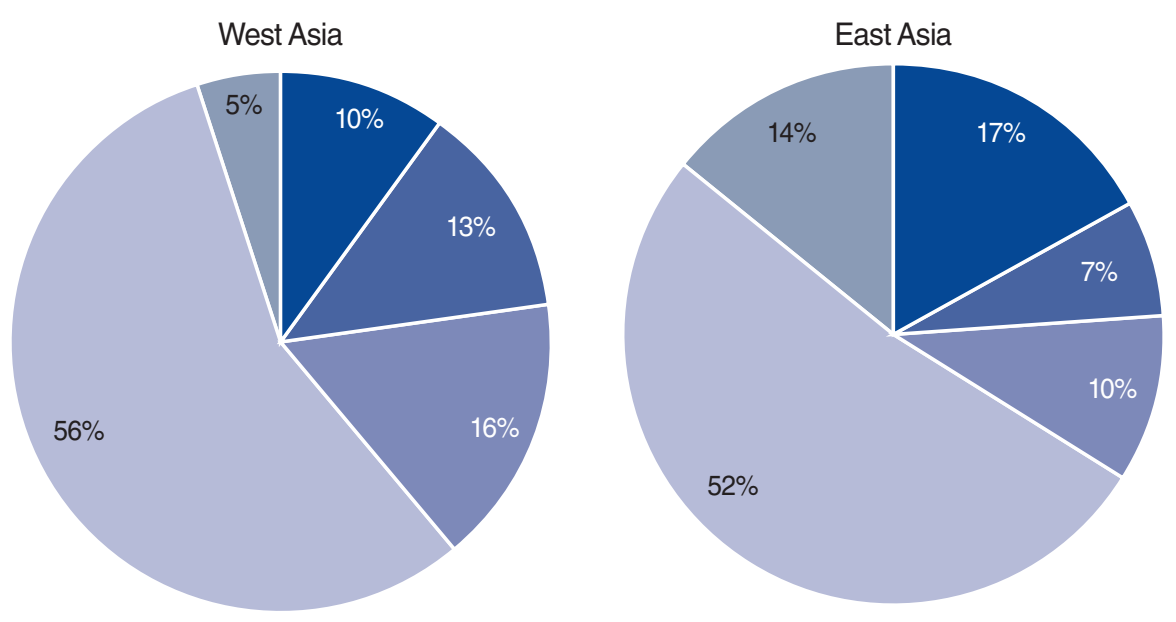
Nonacid reflux
Lack of therapeutic compliance
$\square$ The severity of the reflux
The poor dietary habits and lifestyle of the patient
$\square$ I don't know

Fig. 5. The main reasons for therapeutic failure according to Western and Eastern Asian otolaryngologists. More than $50 \%$ of Western and Eastern Asian otolaryngologists believed that patients' poor dietary habits are the main cause of therapeutic failure (56\% and 52\%, respectively).
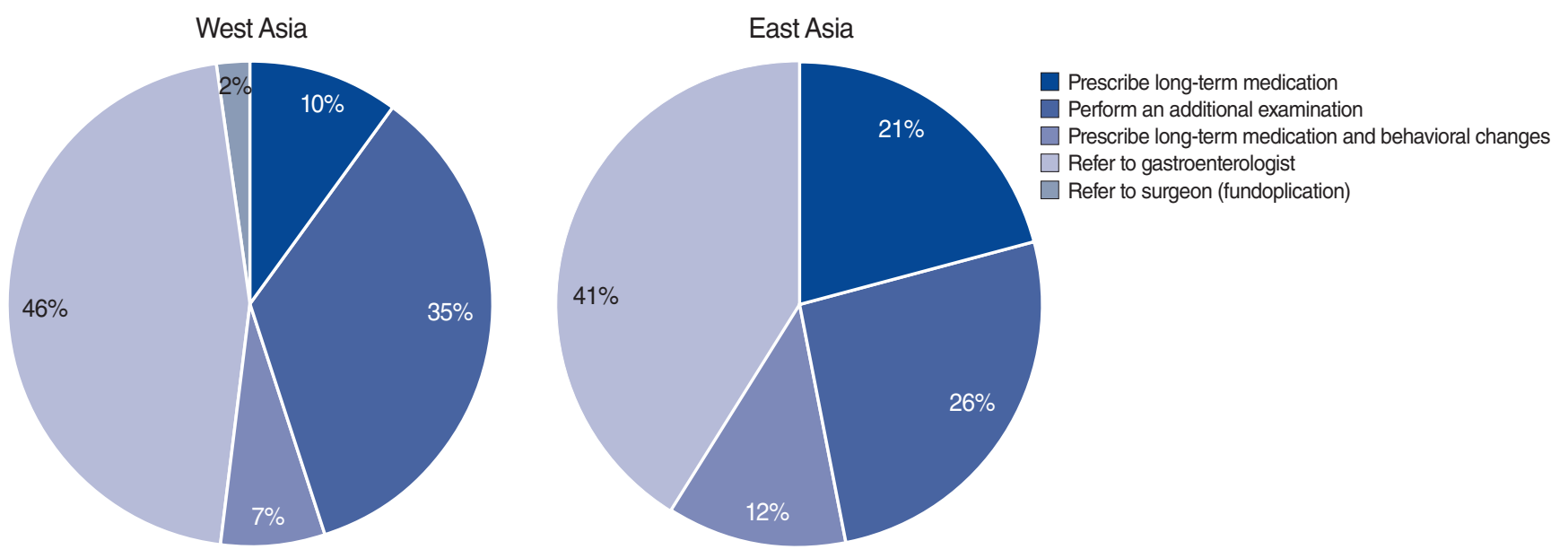

Fig. 6. Therapeutic management of recalcitrant reflux by Western and Eastern Asian otolaryngologists. For the management of recalcitrant laryngopharyngeal reflux, more than $40 \%$ of Western and Eastern Asian otolaryngologists referred the patient to a gastroenterologist (46\% and $41 \%$, respectively) and more than $25 \%$ of them performed an additional examination ( $35 \%$ and $26 \%$, respectively).

therapeutic failure were patients' poor dietary habits and life style (53.8\%); nonacid reflux (14.0\%), and a lack of therapeutic compliance $(9.8 \%)$; furthermore, $9.8 \%$ of otolaryngologists indicated that they did not know the reason for therapeutic failure (Fig. 5). For the management of recalcitrant LPR, $43.7 \%$ of Asian otolaryngologists indicated that they refer the patient to a gastroenterologist, $29.6 \%$ perform an additional examination, and $16.2 \%$ prescribe long-term medication (Fig. 6).

\section{LPR skills}

Almost half (48.6\%) of Asian otolaryngologists considered themselves to be adequately knowledgeable and skilled regarding LPR, while $29.5 \%$ believed the opposite.

\section{DISCUSSION}

The number of publications concerning LPR has dramatically increased since its initial description by Koufman in 1991 [14]. However, there is still no gold standard for the diagnosis and treatment of LPR, and many controversies persist [1]. In a recent study, significant differences in awareness and practices regarding LPR were observed between European otolaryngologists and general practitioners (GPs). Of particular note, only $10.1 \%$ of GPs and $27.4 \%$ of otolaryngologists believed that they were adequately knowledgeable and skilled regarding LPR [15]. This is the first study designed to investigate current practices and opinions of Asian otolaryngologists regarding LPR.

The majority of Asian otolaryngologists considered LPR to be associated with various aerodigestive tract disorders such as Reinke edema, recurrent sore throat, chronic cough, and voice dis- 
orders. Approximately $50 \%$ of them considered LPR to be associated with bronchial hypersensitivity. LPR is thought to be one of the main etiologies causing chronic cough [16], and it might play a role as an etiologic factor in Reinke edema [17]. The finding of a significant association between the RSI and Voice Handicap Index-10 scores suggests that there may be an association between LPR and voice disorders $[18,19]$. Additionally, throat pain might be present in about 70\% of LPR patients [13]. Antireflux therapy may improve pulmonary function and inhibit bronchial hyperresponsiveness in asthmatic patients [20]. In contrast, the survey showed that chronic rhinosinusitis, chronic and acute media otitis, Eustachian dysfunction, vocal fold nodules, vocal fold hemorrhage and polyps, laryngotracheal stenosis, and nasal obstruction were not thought be associated with LPR. However, according to some recent studies, LPR may be associated with acute otitis media [21], Eustachian dysfunction [22], benign vocal fold lesions [23], laryngotracheal stenosis [24], and chronic sinusitis [25]. Based on these associations with LPR, anti-reflux drugs might be considered as additional treatment options for these upper aerodigestive tract diseases.

In a recent systematic review, the most prevalent LPR symptoms were found to be globus sensation, throat clearing, hoarseness, excess throat mucus, and postnasal drip [9], while more than $70 \%$ of the Asian otolaryngologists surveyed in this study considered coughing after lying down or after eating, throat clearing, globus sensation, and chronic cough to be LPR-related symptoms. Interestingly, the opinions of Asian and European otolaryngologists about LPR-related symptoms differ [15]. Stomach acid coming up, cough, hoarseness, and throat pain were considered to be the symptoms most closely related to LPR by European otolaryngologists. These differences in opinion between otolaryngologists from different regions are probably due to heterogeneity in the inclusion and exclusion criteria, diagnostic approaches, and the determination and definition of clinical symptoms [9].

More than $70 \%$ of Asian otolaryngologists considered posterior commissure granulations, arytenoid or laryngeal erythema, and posterior commissure hypertrophy to be closely associated with LPR. Western and Eastern Asian otolaryngologists showed some differences in opinions about the findings that are closely associated with LPR. Several findings, such as vocal fold erythe$\mathrm{ma}$, leukoplakia, posterior pharyngeal wall inflammation, anterior pillar inflammation and coated tongue, are not included in the reflux finding score (RFS) and they were considered to be LPR-associated findings only to a certain extent (by about $10 \%$ to $60 \%$ of respondents). However, the findings associated with LPR may vary according to the type of reflux and patients' symptoms $[26,27]$. In addition, the physician's judgment is strongly influenced by his or her knowledge of the patient's complaint, which may help explain the low inter-rater reliability of the RFS [1]. To compensate for these weaknesses of the RFS, the meaning of each item should be defined more accurately with mini- mum ambiguity. In that respect, the RSA is a new, validated instrument assessing oral, laryngeal, and extra-laryngeal LPR-associated findings in a more descriptive fashion.

A few Asian otolaryngologists used GI endoscopy for the initial assessment of LPR patients. That is probably related to the fact that the majority of Asian otolaryngologists considered LPR and GERD to be different diseases. Both Western and Eastern Asian otolaryngologists prescribed GI endoscopy because of symptoms refractory to medication and the need for long-term PPI therapy. Furthermore, more Eastern Asian otolaryngologists prescribed GI endoscopy for patients complaining of heartburn or stomach acid coming up than Western Asian otolaryngologists. For three decades, the overall trend has been to consider LPR and GERD to be different diseases [2,28], but many studies have shown a relationship between the two diseases $[29,30]$. Thus, digestive symptoms such as heartburn and regurgitationboth considered to be major symptoms of GERD—should be carefully evaluated when diagnosing LPR [13].

More than $70 \%$ of Asian otolaryngologists diagnosed LPR after a positive response to an empirical therapeutic trial. This diagnostic method is widely used globally, and some studies have shown that the use of a standardized LPR management protocol improved the rate of complete response to PPI therapy $[9,19]$. In recent meta-analysis, however, PPI therapy did not show any advantage over placebo in terms of RFS improvement [31]. Furthermore, placebo and PPIs often show similar responses [1].

In fact, MII-pH is the most reliable method for precisely diagnosing LPR, which enables the prescription of an adequate treatment depending on the type of reflux (acid vs. nonacid). However, the majority of Asian otolaryngologists did not use MII-pH because of its inconvenience, cost, lack of time to perform the examination, lack of meaningfulness, and lack of time for training in interpretation. In addition, they were relatively unaware of the existence of nonacid and mixed LPR, which are a main reason for therapeutic failure. MII-pH is an essential tool for diagnosing nonacid or mixed LPR not well treated by prolonged high-dose PPIs $[9,12]$. Nonacid or mixed LPR could require other medications such as alginate or magaldrate to neutralize the mucosa activity of nonconjugated bile salts and trypsin [9]. In other words, the use of MII-pH for patients with LPR-related symptoms could be an important "therapeutic" tool, because it is probably a more cost-effective approach than empirical PPI therapy, and it allows personalized treatment.

Western Asian otolaryngologists more often prescribed twicedaily PPIs, whereas Eastern Asian otolaryngologists preferred to use once-daily PPIs. In one study, twice-daily PPIs seemed to be more efficient than once-daily PPIs [32], whereas another study reported that once- or twice-daily PPIs seemed to have similar treatment effects [33]. In contrast, H2-blockers are not suitable for LPR due to their short duration of action [34]. The current management protocols for LPR recommend a 3-month duration of twice-daily PPIs for empirical treatment followed by symptom 
assessment and titration of medication [9], because the laryngopharyngeal findings associated with LPR require at least 2 months to improve [34]. Additionally, most Asian otolaryngologists considered diet to be an important factor affecting LPR treatment. In a recent meta-analysis, dietary and behavioral changes were found to be important factors that modulated the therapeutic effectiveness of PPIs [1]. In addition, alkaline and low-fat diets showed positive effects in the treatment of suspected LPR and recalcitrant LPR [35-37].

The LPR treatment response rate was evaluated as being from $10 \%$ to $40 \%$ by more than $70 \%$ of Asian otolaryngologists. Both Western and Eastern Asian otolaryngologists believed that the most frequent cause of resistance to LPR treatment is patients' poor dietary habits, followed by nonacid LPR. Dietary and lifestyle changes were found to be important factors in the management of LPR in a recent meta-analysis [1]. We also have to consider patients' compliance as an important cause of recalcitrant LPR. In a recent study, about $60 \%$ of LPR patients did not adequately take the medication [38].

In comparison to a previous study about the awareness of European otolaryngologists and GPs of LPR [15], the main strength of this study is it analyzed the opinions and awareness of only otolaryngologists in the Asian region. Furthermore, many Asian otolaryngologists (146 subjects) completed the survey, thereby allowing a comparison of otolaryngologists' practices with respect to LPR between Western and Eastern Asia. Some factors that were found to differ between Western and Eastern Asia should be studied in future studies (e.g., dietary differences and the prevalence of various esophageal findings). Further similar studies of otolaryngologists or gastroenterologists from other areas will be helpful for identifying common practices in the diagnosis and treatment of LPR, with the ultimate goal of establishing a more appropriate management algorithm.

In conclusion, this study revealed many similarities and differences between Western and Eastern Asian otolaryngologists regarding LPR. Notably, $50 \%$ of Asian otolaryngologists believed that they were adequately knowledgeable and skilled regarding LPR. Further efforts are needed to improve the awareness and knowledge of Asian otolaryngologists of LPR. Although many Asian otolaryngologists were not aware of its usefulness, MII-pH should be considered as a valuable diagnostic tool, and it may be a more cost-effective approach than previously presumed. Otolaryngologists can detect nonacid and mixed LPR using MII$\mathrm{pH}$, and prescribe personalized treatments including PPIs and/ or alginate or magaldrate. In cases of recalcitrant LPR symptoms, otolaryngologists must investigate patients' diet, lifestyle, therapeutic compliance, and the profile of reflux (nonacid or mixed) before performing an additional examination. A more clearly defined framework for the diagnosis and management of LPR would be helpful for otolaryngologists.

\section{CONFLICT OF INTEREST}

No potential conflict of interest relevant to this article was reported.

\section{ACKNOWLEDGMENTS}

This research was supported by a grant of the Korea Health Technology R\&D Project through the Korea Health Industry Development Institute, funded by the Ministry of Health \& Welfare, Republic of Korea (grant no. HI18C1039).

\section{ORCID}

Su Il Kim

Jerome R. Lechien

https://orcid.org/0000-0002-9647-3034

Tareck Ayad

Huan Jia

https://orcid.org/0000-0002-0845-0845

https://orcid.org/0000-0003-3673-7875

Seyyedeh Maryam Khoddami

https://orcid.org/0000-0003-2689-5976

https://orcid.org/0000-0003-0070-1643

Necati Enver https://orcid.org/0000-0002-3161-8810

Sampath Kumar Raghunandhan

https://orcid.org/0000-0001-6964-1066

Abdul Latif Hamdan $\quad$ https://orcid.org/0000-0003-1493-3568

Young-Gyu Eun

https://orcid.org/0000-0003-4081-5207

\section{AUTHOR CONTRIBUTIONS}

Conceptualization: JRL, TA, ALH, YGE. Data curation: HJ, SMK, NE, SKR, ALH, YGE. Formal analysis: SIK, JRL, ALH, YGE. Funding acquisition: YGE. Methodology: all authors. Project administration: JRL, ALH, YGE. Visualization: SIK, JRL. Writingoriginal draft: SIK, JRL, YGE. Writing-review \& editing: all authors.

\section{SUPPLEMENTARY MATERIALS}

Supplementary materials can be available at https://doi.org/10. 21053/ceo.2019.01669.

\section{REFERENCES}

1. Lechien JR, Saussez S, Schindler A, Karkos PD, Hamdan AL, Harmegnies B, et al. Clinical outcomes of laryngopharyngeal reflux treatment: a systematic review and meta-analysis. Laryngoscope. 2019 May; 129(5):1174-87.

2. Mosli M, Alkhathlan B, Abumohssin A, Merdad M, Alherabi A, Marglani $\mathrm{O}$, et al. Prevalence and clinical predictors of LPR among pa- 
tients diagnosed with GERD according to the reflux symptom index questionnaire. Saudi J Gastroenterol. 2018 Jul-Aug;24(4):236-41.

3. Koufman JA, Aviv JE, Casiano RR, Shaw GY. Laryngopharyngeal reflux: position statement of the committee on speech, voice, and swallowing disorders of the American Academy of OtolaryngologyHead and Neck Surgery. Otolaryngol Head Neck Surg. 2002 Jul; 127(1):32-5.

4. Eusebi LH, Ratnakumaran R, Yuan Y, Solaymani-Dodaran M, Bazzoli F, Ford AC. Global prevalence of, and risk factors for, gastro-oesophageal reflux symptoms: a meta-analysis. Gut. 2018 Mar;67(3):430-40.

5. KamaniT, Penney S, Mitra I, Pothula V.The prevalence of laryngopharyngeal reflux in the English population. Eur Arch Otorhinolaryngol. 2012 Oct;269(10):2219-25.

6. Spantideas N, Drosou E, Bougea A, Assimakopoulos D. Laryngopharyngeal reflux disease in the Greek general population, prevalence and risk factors. BMC Ear Nose Throat Disord. 2015 Dec;15:7.

7. Chen XM, LiY, GuoWL, Wang WT, Lu M. Prevalence of laryngopharyngeal reflux disease in Fuzhou region of China. Zhonghua Er Bi Yan Hou Tou Jing Wai Ke Za Zhi. 2016 Dec;51(12):909-13.

8. Kim SI, Kwon OE, Na SY, Lee YC, Park JM, Eun YG. Association between 24-hour combined multichannel intraluminal impedance-pH monitoring and symptoms or quality of life in patients with laryngopharyngeal reflux. Clin Otolaryngol. 2017 Jun;42(3):584-91.

9. Lechien JR, Akst LM, Hamdan AL, Schindler A, Karkos PD, Barillari MR, et al. Evaluation and management of laryngopharyngeal reflux disease: state of the art review. Otolaryngol Head Neck Surg. 2019 May;160(5):762-82.

10. Gupta N, Green RW, Megwalu UC. Evaluation of a laryngopharyngeal reflux management protocol. Am J Otolaryngol. 2016 May-Jun; 37(3):245-50.

11. Altman KW, Stephens RM, Lyttle CS, Weiss KB. Changing impact of gastroesophageal reflux in medical and otolaryngology practice. Laryngoscope. 2005 Jul;115(7):1145-53.

12. Johnston N, Ondrey F, Rosen R, Hurley BP, Gould J, Allen J, et al. Airway reflux. Ann NYAcad Sci. 2016 Oct;1381(1):5-13.

13. Lechien JR, Bobin F, Muls V, Thill MP, Horoi M, Ostermann K, et al. Validity and reliability of the reflux symptom score. Laryngoscope. 2020 Mar;130(3):E98-107.

14. Koufman JA.The otolaryngologic manifestations of gastroesophageal reflux disease (GERD): a clinical investigation of 225 patients using ambulatory 24-hour $\mathrm{pH}$ monitoring and an experimental investigation of the role of acid and pepsin in the development of laryngeal injury. Laryngoscope. 1991 Apr;101(4 Pt 2 Suppl 53):1-78.

15. Lechien JR, Mouawad F, Mortuaire G, Remacle M, Bobin F, Huet K, et al. Awareness of European otolaryngologists and general practitioners toward laryngopharyngeal reflux. Ann Otol Rhinol Laryngol. 2019 Nov;128(11):1030-40.

16. Michaudet C, Malaty J. Chronic cough: evaluation and management. Am Fam Physician. 2017 Nov;96(9):575-80.

17. Wang JS, Li JR. The role of laryngopharyngeal reflux in the pathogenesis of Reinke's edema. Lin Chung Er Bi Yan Hou Tou Jing Wai Ke Za Zhi. 2016 Dec;30(24):1931-4.

18. Alanazi R, Alrahim A, Bayounos S, Al-Ghuwainem A, Al-Bar MH. Association between voice handicap index and reflux symptom index: a cross-sectional study of undiagnosed general and teacher cohorts in Saudi Arabia. Sultan Qaboos Univ Med J. 2018 Aug;18(3): e350-4.

19. Lechien JR, Finck C, Khalife M, Huet K, Delvaux V, Picalugga M, et al. Change of signs, symptoms and voice quality evaluations throughout a 3- to 6-month empirical treatment for laryngopharyngeal reflux disease. Clin Otolaryngol. 2018 Oct;43(5):1273-82.

20. Jiang SP, Liang RY, Zeng ZY, Liu QL, Liang YK, Li JG. Effects of an- tireflux treatment on bronchial hyper-responsiveness and lung function in asthmatic patients with gastroesophageal reflux disease. World J Gastroenterol. 2003 May;9(5):1123-5.

21. Miura MS, Mascaro M, Rosenfeld RM.Association between otitis media and gastroesophageal reflux: a systematic review. Otolaryngol Head Neck Surg. 2012 Mar;146(3):345-52.

22. Al-Saab F, Manoukian JJ, Al-Sabah B, Almot S, Nguyen LH, Tewfik TL, et al. Linking laryngopharyngeal reflux to otitis media with effusion: pepsinogen study of adenoid tissue and middle ear fluid. J Otolaryngol Head Neck Surg. 2008 Aug;37(4):565-71.

23. Lechien JR, Saussez S, Nacci A, Barillari MR, Rodriguez A, Le Bon $\mathrm{SD}$, et al. Association between laryngopharyngeal reflux and benign vocal folds lesions: a systematic review. Laryngoscope. 2019;129(9): E329-41.

24. Toohill RJ, Ulualp SO, Shaker R. Evaluation of gastroesophageal reflux in patients with laryngotracheal stenosis. Ann Otol Rhinol Laryngol. 1998 Dec;107(12):1010-4.

25. LoehrlTA, Samuels TL, Poetker DM, Toohill RJ, Blumin JH, Johnston N.The role of extraesophageal reflux in medically and surgically refractory rhinosinusitis. Laryngoscope. 2012 Jul;122(7):1425-30.

26. Lee YC, Kwon OE, Park JM, Eun YG. Do laryngoscopic findings reflect the characteristics of reflux in patients with laryngopharyngeal reflux? Clin Otolaryngol. 2018 Feb;43(1):137-43.

27. Chang BA, MacNeil SD, Morrison MD, Lee PK. The reliability of the reflux finding score among general otolaryngologists. J Voice. 2015 Sep;29(5):572-7.

28. Koufman JA. Laryngopharyngeal reflux is different from classic gastroesophageal reflux disease. Ear Nose Throat J. 2002 Sep;81(9 Sup$\mathrm{pl}$ 2):7-9.

29. Jaspersen D, Kulig M, Labenz J, Leodolter A, Lind T, Meyer-Sabellek W, et al. Prevalence of extra-oesophageal manifestations in gastrooesophageal reflux disease: an analysis based on the ProGERD Study. Aliment Pharmacol Ther. 2003 Jun;17(12):1515-20.

30. Patel D, Vaezi MF. Normal esophageal physiology and laryngopharyngeal reflux. Otolaryngol Clin North Am. 2013 Dec;46(6):1023-41.

31. Guo H, Ma H, Wang J. Proton pump inhibitor therapy for the treatment of laryngopharyngeal reflux: a meta-analysis of randomized controlled trials. J Clin Gastroenterol. 2016 Apr;50(4):295-300.

32. Park W, Hicks DM, Khandwala F, Richter JE, Abelson TI, Milstein C, et al. Laryngopharyngeal reflux: prospective cohort study evaluating optimal dose of proton-pump inhibitor therapy and pretherapy predictors of response. Laryngoscope. 2005 Jul;115(7):1230-8.

33. Yoon YH, Park KW, Lee SH, Park HS, Chang JW, Koo BS. Efficacy of three proton-pump inhibitor therapeutic strategies on laryngopharyngeal reflux disease; a prospective randomized double-blind study. Clin Otolaryngol. 2019 Jul;44(4):612-8.

34. Postma GN, Johnson LF, Koufman JA. Treatment of laryngopharyngeal reflux. Ear Nose Throat J. 2002 Sep;81(9 Suppl 2):24-6.

35. Koufman JA. Low-acid diet for recalcitrant laryngopharyngeal reflux: therapeutic benefits and their implications. Ann Otol Rhinol Laryngol. 2011 May;120(5):281-7.

36. Zalvan CH, Hu S, Greenberg B, Geliebter J. A comparison of alkaline water and Mediterranean diet vs proton pump inhibition for treatment of laryngopharyngeal reflux. JAMA Otolaryngol Head Neck Surg. 2017 Oct;143(10):1023-9.

37. Lechien JR, Huet K, Khalife M, De Marrez LG, Finck C, Harmegnies $\mathrm{B}$, et al. Alkaline, protein, low-fat and low-acid diet in laryngopharyngeal reflux disease: our experience on 65 patients. Clin Otolaryngol. 2019 May;44(3):379-84.

38. Pisegna JM, Yang S, Purcell A, Rubio A. A mixed-methods study of patient views on reflux symptoms and medication routines. J Voice. 2017 May;31(3):381. 